\title{
GREY BOX MODELING STRATEGY APPLIED TO A WATER TANK HEAT SYSTEM (WTHS)
}

\author{
Márcio Lindemberg Bezerra de Medeiros ${ }^{1, a}$, Emanuel Benício de Almeida \\ Cajueiro $^{a}$
}

SENAI CIMATEC, Post Degree in Automation, Control and Robotics. SalvadorBA, Brazil.

\begin{abstract}
This paper presents a Water Tank Heating System (WTHS) with the phenomenal modeling along with a system identification procedure in order to demonstrate a typical methodology of how to estimate the unknown parameters (grey box modeling). Simulations were run in a reservoir with 11 liters of fresh water using a $110 \mathrm{~V}, 1300 \mathrm{~W}$ set of resistance, temperature sensor and a fan to create a forced heat convection transference. A set of PRBS was applied and the system response recorded using a PLC. Using MATLAB identification tool box an ARX model with up to $58 \%$ fitness was obtained. Non-linear and approached linear models were simulated fitting with $87 \%$ for the last compared with the first. The mathematical model developed can be used as a virtual sensor replacing a physical assembly bringing cost reductions and advantages such as time invariance, no maintenance, nor failures, nor electromagnetic interference.
\end{abstract}

Keywords: modeling; heat water tank; system identification.

\section{ESTRATÉGIA DE MODELAGEM CAIXA CINZA APLICADA A UM SISTEMA DE TANQUE DE AQUECIMENTO DE ÁGUA}

Resumo: Esse artigo apresenta a modelagem fenomenológica e o procedimento de identificação de sistemas para um protótipo de sistema de aquecimento de tanque de água com o objetivo de demonstrar a metodologia tipicamente utilizada para avaliação de parâmetros desconhecidos (modelagem caixa cinza). Simulações foram realizadas em um reservatório contendo 11 litros de água usando um conjunto de resistências de $110 \mathrm{~V}, 1300 \mathrm{~W}$, um sensor de temperatura e um ventilador para criar uma convecção forçada. Um sinal PRBS foi aplicado e a resposta do sistema registrada usando um CLP. Usando o tool box do MATLAB para identificação de sistemas um modelo ARX foi encontrado com ajuste de até 58\%. Os modelos não-linear e linear foram simulados com ajuste de $87 \%$ deste último frente ao primeiro. $O$ modelo matemático desenvolvido pode ser usado como sensor virtual trazendo redução de custos e vantagens tais como invariância temporal, inexistência de manutenção, inexistência de falhas, nem interferências eletromagnéticas.

Palavras-chave: modelagem; tanque de aquecimento; identificação de sistemas. 


\section{INTRODUCTION}

Water tank are used for a wide variety of industrial processes of far different areas including pharmaceutical, foods and beverages, petrochemical and so on. In order to design a proper temperature controller, knowledge of the dynamic is essential. Most of phenomenological modeling may generate a non-linear model since all dynamic systems will show more or less aspects of non-linearity [1]. Complexity, uncertainties and unknow parameters may lead to a complete discouragement of the modeling task. A detailed work for a hot pump water heat cycle is presented in [2]. Linear approaches may sound inviting, especially due to the existing of vast tools developed for control design, but, this last, has some limited application for larges excursions of process variables, which normally may occur, leading to eventual useless linear approached model, understanding that new steady condition requires another linearization point, which may result in a different response from the linear model. When a nonlinear process need be faced in its detailed complexities, one option is to apply neural networks like can be observed in the work of [3] for domestic hot water prediction. On the other hand, for many situations demanding agility and faster practical implementation, a black box polynomial modeling like ARX (Auto Regressive with Exogenous Inputs) surely would be the solution, all the previous discussion in mind. The authors in [4] have embarked in this option for a similar system of this paper.

Considering that a water heating system is relatively simple to model but some parameter as the convection coefficient $h$ may not be promptly available, in this paper, the grey box modeling has been selected. Data acquisition and phenomenological results will then provide the reference for qualitative and quantitative performance evaluation of the results obtained through system identification.

\section{METHODOLOGY}

The case study is illustrated in Figure 1 below and is comprised of a stainless steel reservoir with 11 liters of water volume, a set of resistances of $110 \mathrm{~V}, 1300 \mathrm{~W}$ operating in an on-off mode. To measure the temperature, a pt-100 sensor has been used. The reservoir has a very thin wall thickness in order to minimize heat conduction. To avoid heat transference through the bottom, the reservoir possesses four plastic wheels. To favor the heat removal out of the system, a fan was positioned in front of the tank.

Figure 1 - Arrangement of water tank heating system.

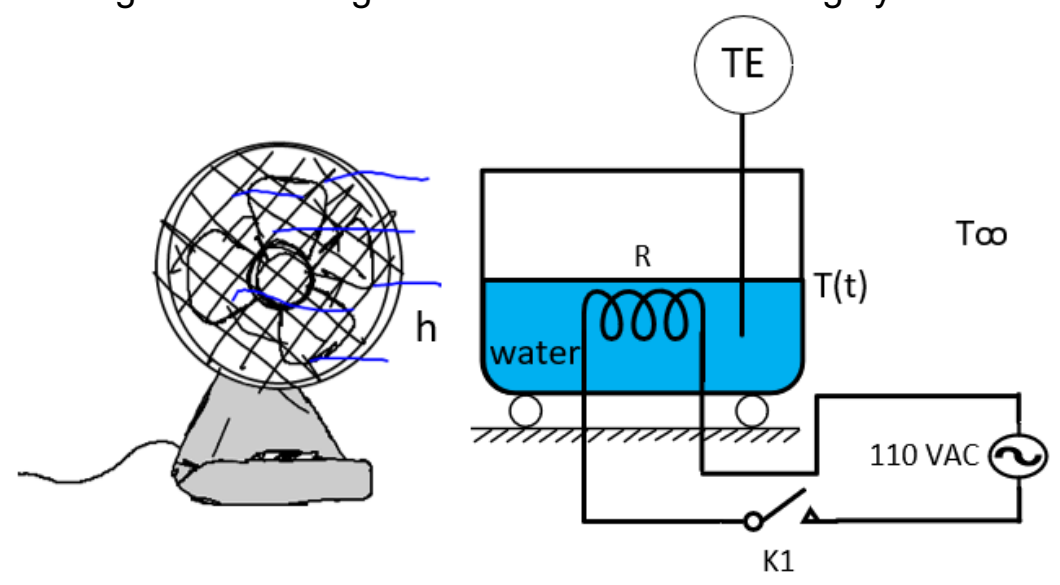




\subsection{Mathematical Modeling (concentrated parameters)}

Some assumptions are necessary for simplification. None of them have major impact upon the dynamics for the considered prototype. Then, the ambient temperature, $T_{\infty}$, the specific heat $C_{p}$, and the convection coefficient, $h$, are all kept as constants. This last parameter is the unknown to be found using superposition. Resistance power and voltage are $1300 \mathrm{~W} \times 110 \mathrm{VAC}$ respectively. The heat transference from the water to the environment is assumed to occur exclusively through the lateral area of the cylindrical reservoir of $0,343 \mathrm{~m}$ of diameter and total height of $0,350 \mathrm{~m}$. The water volume is 11 liters. Water density is rounded to 1000 $\mathrm{kg} / \mathrm{m}^{3}$.

\subsubsection{Phenomenological Model Determination}

Energy balance combined with second Ohm's law yields in Equation (1) [5].

$$
\frac{d T}{d t}=\frac{V^{2}(t)-h A_{s} R\left(T(t)-T_{\infty}\right)}{R m C_{p}}
$$

Where $T(t)$ is the water temperature in Celsius, $V(t)$ is the tension applied in Volts, $h$ is the convection heat transference coefficient in $\frac{W}{m^{2} K}, A_{s}$ is the surface of heat transference in $m^{2}, R$ is the resistance in Ohms, $m$ is the water mass in $\mathrm{kg}$ and $C_{p}$ is the water specific heat in $\frac{J}{K g K}$.

\subsubsection{Model Linearization}

Taking the notation $f=\frac{d T}{d t}$, where $f_{L I N}$ is the linear approximation of $\frac{d T}{d t}$ obtained from Taylor's series, defining the stationary values $\bar{f}, \bar{V}, \bar{T}$ and the deviation variables $f^{\prime}, V^{\prime}, T^{\prime}$, generate the Equations (2) to (4).

$$
\begin{gathered}
f \cong f_{L I N}=\bar{f}+\frac{\partial f}{\partial V}(V(t)-\bar{V})+\frac{\partial f}{\partial T}(T(t)-\bar{T}) \\
f^{\prime}=f_{L I N}-\bar{f}, \quad V^{\prime}=V(t)-\bar{V}, T^{\prime}=T(t)-\bar{T} \\
f=\frac{\partial f}{\partial V} V^{\prime}+\frac{\partial f}{\partial T} T^{\prime}
\end{gathered}
$$

\subsubsection{Laplace's Transform and Transfer Function (TF)}

Applying Laplace to Equation (4) and performing some algebraic manipulation the first order TF is defined as:

With

$$
\frac{T(s)}{V(s)}=\frac{\frac{-\frac{\partial f}{\partial V}}{\frac{\partial f}{\partial T}}}{\frac{-1}{\frac{\partial f}{\partial T}} s+1}=\frac{K_{p}}{\tau_{p} s+1}
$$

$$
K_{p}=\frac{2 \bar{V}}{R h A_{s}} \text { and } \quad \tau_{p}=\frac{m C_{p}}{h A_{s}}
$$




\subsection{System Identification}

A Pseudo Random Binary Signal (PRBS), $u_{1}$, was applied to the WTHS. Binary because the resistance may assume only two values, either $0(0 \mathrm{~V})$ or $1(110 \mathrm{~V})$. Pseudo random is achieved using the ladder instruction shift bit to the right (SHR). Using the $5^{\text {th }}$ and $6^{\text {th }}$ bits of the byte, applying them in an Exclusive OR digital port (XOR) and feeding back the result in a logical AND with a pulsing TIMER, a repeated signal can be achieved with a period of 63 times TIMER activation [6]. Sampling time, $t_{s}$ is 1 second and TIMER set, $t_{b}$ to 30 seconds. Test with PRBS after trigger has long 7279 seconds.

\section{RESULSTS AND DISCUSSION}

\subsection{System Identification Results}

Temperature stabilization, $\bar{T}$, when heat flow in and out were quiet the same, $\dot{Q}_{\text {in }} \cong \dot{Q}_{\text {out }}$, was close to 53 degrees and then the trigger for PRBS has been given. The average temperature from recorded data was $T_{\text {avg }}=53,6^{\circ} \mathrm{C}$. Figure 2 shows the data recorded ( $u 1$ is the voltage and $y 1$ is the temperature).

Figure 2 - Data recorded.

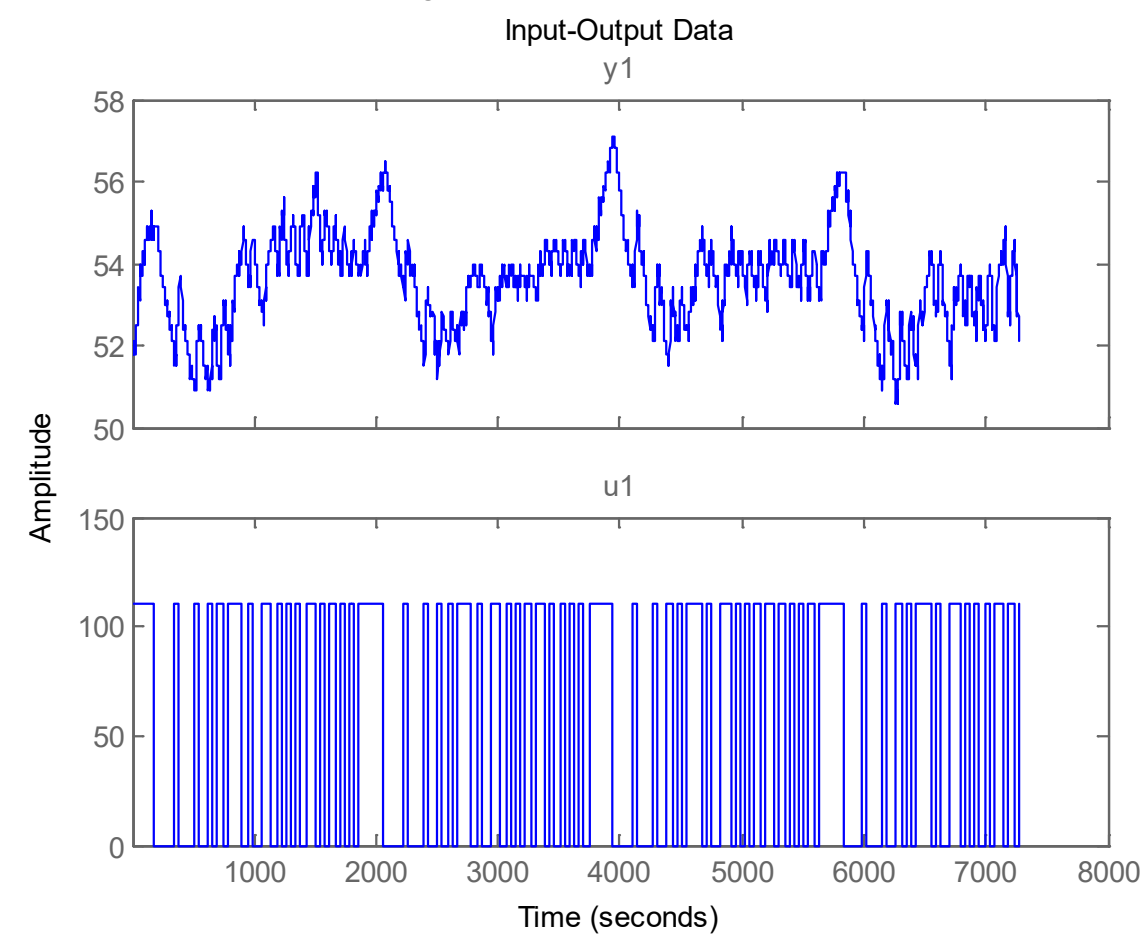

For identification procedure, an emphasis about the models have been put to the simplest ones which would be useful, say it for controller design. Data separated in two adjunct subsets have resulted the discrete TF in Equation (7) with fitness of $58,7 \%$.

$$
G(z)=\frac{0.0003261 z^{-10}}{1-0.9979 z^{-1}}
$$

After performing the identification procedure that resulted in (7), a new preprocessing was applied, this time with the data split into two sub sets interspersed. The result obtained showed a fit of $54,4 \%$ with the discrete FT presented in Equation (8). 


$$
G(z)=\frac{0.0006861 z^{-7}}{1-0.9953 z^{-1}}
$$

\subsection{Modeling Results}

Mathematical non-linear model was simulated in SIMULINK and TF was calculated with $\quad m=11.08 \mathrm{~kg}, A s=0.377 \mathrm{~m}^{2}, R=9.3 \Omega, T_{\infty}=297.15 \mathrm{~K}, \bar{T}=$ $326.77 \mathrm{~K}, C_{p}=4180 \frac{\mathrm{J}}{\mathrm{KgK}}$. In order to make match the non-linear model and the linear TF with the acquired data, the unknown parameter $h$ was tested with a reasonable good visual match for the value of $58 \frac{\mathrm{W}}{\mathrm{m}^{2} \mathrm{~K}}$, resulting in the continuous TF depicted in Equation (9).

$$
G(s)=\frac{0.541}{2119 s+1}
$$

\subsection{Results Comparison}

Both discrete TFs exhibit very similar pole, close values for delay but with different static gains. Both produces similar outputs for the experiment inputs.

This study has generated four models which are all together plotted against the data acquired in Figure 3. Linear approach (Equation 9) has a fit of $87,6 \%$ compared with the non-linear model (Equation 1).

Figure 3 - Data acquired compared with different 04 models.

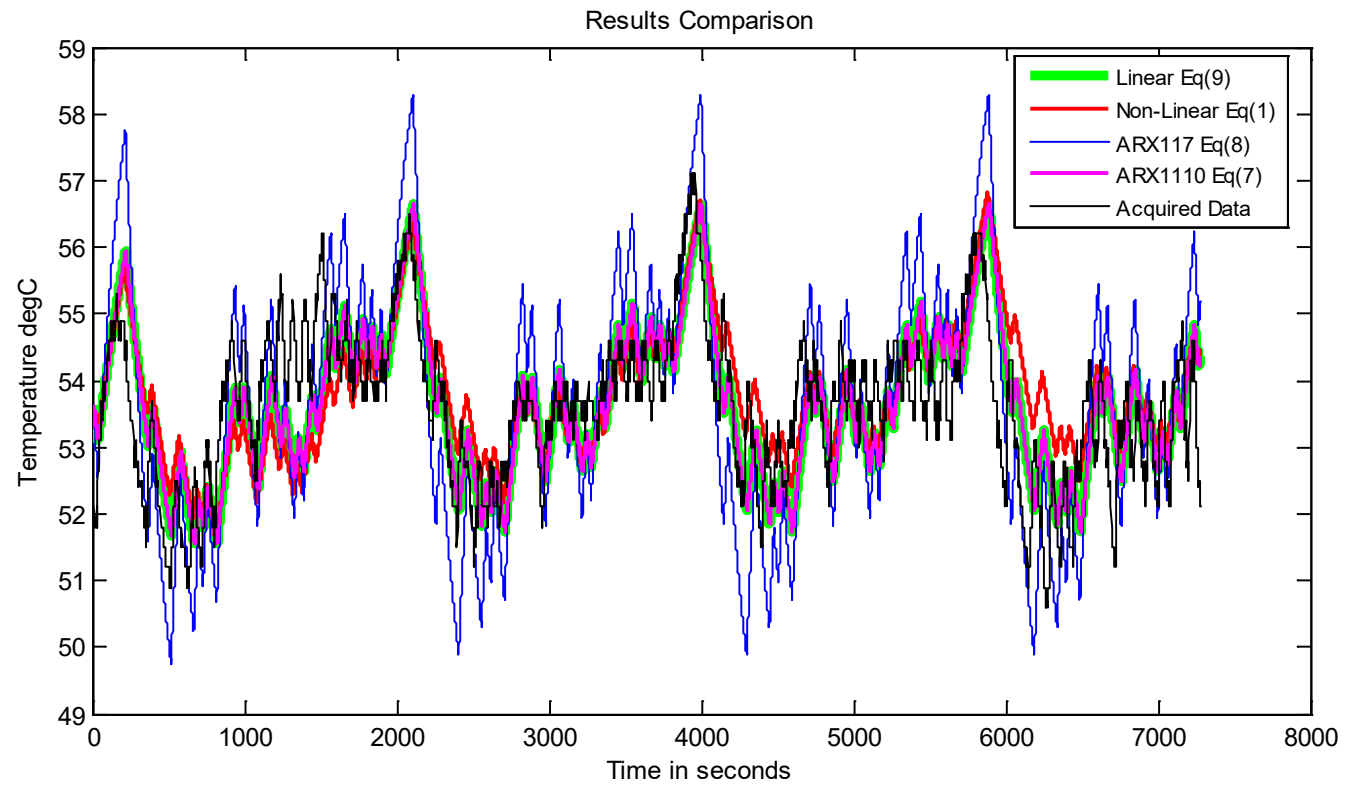




\section{CONCLUSION}

All the models have closely matched the experiment data. Mathematical nonlinear and linear models were quite the same because non-linearities are week and had been not emphasized in the linearization. Mathematical models have considered a perfect square voltage input signal which in fact is just an approximation. The unknow parameter $\boldsymbol{h}$ was properly determined by superimposing model to the data. Results from system identification have produced very close results for both pre-processing procedures.

\section{REFERENCE}

1SEBORG, Dale E.; EDGAR, Thomas F.; MELLICHAMP, Duncan A.; DOYLE, Francis J. Process Dynamics and Control. 3. Ed. WILLEY, 2011.

2DEUTZ, K. R. CAURET, Odile. RULLIĖRE, Romuald. HABERSCHILL, Philippe. Modeling and Experimental Study of a Heat Pump Water Heater Cycle. Purdue University Purdue e-Pubs. International Refrigeration and Air Conditioning. Conference School of Mechanical Engineering. 2016

${ }^{3}$ KENDEL, Gillot, GRAHAM, Mark. An Artificial Neural Netword for Predicting Domestic Hot Water Characteristics. International Journal of Low-Carbon Technologies 4(2): 112-119, June, 2009.

${ }^{4}$ ARAS, M.S.M; BASAR, M. F.; HASIM, N. KAMARUDDIN, M.N. JAAFAR, H.I. Development and Modeling of Water Tank System Using System Identification Method. International Journal of Engineering and Advanced Technology (IJEAT)

ISSN: 2249 - 8958, Volume-2, Issue-6, August 2013

${ }^{5}$ Çengel, Y. A.; Ghajar, A. J. Heat and mass transfer: Fundamentals \& applications. New York: McGraw-Hill, 2011.

${ }^{6}$ AGUIRRE, LUIZ. Introdução à Identificação de Sistemas: Técnicas Lineares e Não Lineares. 4.ed. Editora UFMG, 2015. 